\title{
nature
}

\section{A good week for the world}

\section{It would be hard not to be optimistic after last week's progress on arms control. But the next step will require some much more fundamental changes in thinking.}

THIs has been a busy week for negotiators around the world, but especially so for those in the United States and the Soviet Union. In Montreal, representatives of 24 nations hammered out a treaty that will limit the use of chlorofluorocarbons, increasingly implicated as playing a critical role in the complex chemistry of the upper atmosphere (see page 277). Later in the week, the Kremlin and the White House announced to the world that the basis for a treaty on intermediate nuclear weapons had been agreed upon, the details of which would be cleared up before a summit between Mr Reagan and Mr Gorbachev takes place sometime before the end of the year.

Negotiating the treaty, difficult as it may bc, is only one of an interlocking series of moves that is required if the world is to change the way it conducts its business. Even as President Reagan proudly announced his arms-control achievements, the Senate voted to curtail certain experiments contemplated by the Pentagon as part of the president's Strategic Defense Initiative (SDI) because they would violate the antiballistic missile (ABM) treaty. The Reagan administration has sought to show that SDI and ABM are not incompatible acronyms, but even conservative Congressmen find it hard to stretch conscientiously the language of the latter to include all the activities required by the former.

Negotiators in Montreal can be justifiably proud of their accomplishments. Although it would be pleasing to have clearcut answers about how chlorofluorocarbons affect ozone concentrations in the atmosphere, the certainty that there is now no way to coax them out of the atmosphere once they are released into it must certainly make countries consider the implications of using them, especially now that the link to adverse consequences can be reasonably postulated. Although some will argue that the restrictions on the use of chlorofluorocarbons have not gone far enough, the very fact that restrictions went beyond what seemed possible a few years ago should make those desiring greater reductions confident that they are not being ignored. This is a time to treat the world's cup of environmental consciousness as half-full, rather than half-empty.

\section{Defiance}

Similarly, it is possible to look critically at what was not accomplished between the Soviet Union and the United States in their new agreement without losing a sense of optimism. The Soviet Union would like to see ABM strengthened, with the intention of putting an end to SDI. The United States does not find that appealing. Indeed, at the end of the week Secretary of Defense Caspar Weinberger gave formal approval to a series of SDI tests that - while staying within the currently accepted boundaries of ABM - must seem defiant given the spirit of agreement in the air in Washington. There is also little more than hopeful noises of progress toward an agreement reducing numbers of long-range strategic weapons. Even the current agreement on short- and intermediate-range missiles has problems that must be solved regarding timetables and verification.

But much has been achieved and an agreement, even if it is not complete, can engender the good will that is necessary but not sufficient for further agreement. The United States will eliminate its ground-launched cruise missiles deployed throughout Europe and its Pershing 2 missiles currently deployed in West Germany. The Soviet Union will remove its SS-20 and SS-4 intermediate-range weapons and its short-range SS-12 and SS-23 missiles. That the European nations have been persuaded that this arrangement is in their best interests is in itself remarkable, as is the Soviet Union's acceptance that discussion of British and French nuclear forces, which are to all practical purposes the same as the weapons now to be removed, should be put on one side for the time being.

\section{Warming}

A flurry of activity may be expected to follow in the wake of the warming of relations between the Soviet Union and the United States. Scientific cooperation is likely to be one beneficiary. Already there is welcome talk of new initiatives in oceanic experiments, in assessing the scope of the depletion of ozone from the atmosphere and in expanding the number of exchanges of scientific personnel that have, under the Reagan administration, become largely a matter of individual initiative. There is even the possibility of some progress in devising a more rational international division of labour in the study of the practical use of nuclear fusion. Progress in these areas provides optimism that the larger differences separating the two superpowers may yet be resolved.

Agreement has come this far without President Reagan having to bite the bullet and make concessions on the timetable for the development and deployment of SDI. But unless the Soviet Union makes a surprising turnabout, progress towards a more complete agreement on long-range nuclear weapons will certainly involve some form of decision not to deploy weapons in space. Reagan's own very human desire to see a strategic arms treaty take shape before the end of his term of office will, paradoxically, be made the harder to realize by his belief that strong support for SDI has helped win the present agreement from the Soviet Union. Nor can SDI be disentangled from another issue, that of nuclear testing, that will almost certainly have to be resolved before agreement can be reached on a wider range of arms-control issues.

The Union of Concerned Scientists estimates that the United States has spent some $\$ 9,000$ million building and deploying the weapons it has now agreed to scrap. But even this massive throw away will not compensate for the build-up in the long-range nuclear arsenal that has occurred under Reagan. The move from an agreement on intermediate-range missiles, where both the Soviet Union and the United States could gain clear political advantages in Europe without either having to make concessions that fundamentally threaten their security, to an agreement to reduce the number of long-range nuclear weapons, is a step that to be accomplished successfully will require a massive leap of the imagination. If Reagan is to look back on his period in office as one that brought about decisive progress, he will have to find some way soon to match hints of Soviet flexibility on continued research on SDI with his own hints that the Senate view of the ABM treaty could have something to recommend it. 